\title{
Effects of Beta-Blockers on Cardiovascular Events and Mortality in Dialysis Patients: A Systematic Review and Meta-Analysis
}

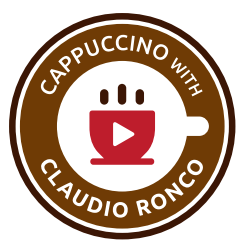

\author{
Jingjing Jin ${ }^{a}$ Xiaoyang Guo ${ }^{b}$ Qiyao Yuc
}

a Department of Nephrology, The Fourth Hospital of Hebei Medical University, Shijiazhuang, PR China; ${ }^{b}$ Department of Nephrology, Xingtai People's Hospital, Xingtai, PR China; ' Department of Scientific Research, The Fourth Hospital of Hebei Medical University, Shijiazhuang, PR China

\section{Keywords}

Beta-blockers · Dialysis · Mortality · Meta-analysis

\begin{abstract}
Background: The effects of beta-blockers are uncertain in dialysis patients. Except antihypertension, $\beta$-blockers may play a unique cardiovascular protective role in the population. This meta-analysis aimed to explore the effects of $\beta$-blockers therapy in adult patients treated with dialysis. Methods: We searched MEDLINE, EMBASE, and the Cochrane library from inception to May 2018 for randomized controlled trials (RCTs) and observational studies about the role of $\beta$-blockers on all-cause mortality, cardiovascular mortality, cardiovascular events, or hospitalizations in dialysis population. Results: Three RCTs and 9 observational studies met the predefined inclusion criteria. The RCTs showed significant association between $\beta$-blockers and reduced all-cause mortality ( $n=363$; risk ratio [RR] $0.73 ; 95 \% \mathrm{Cl} 0.54-0.97)$, cardiovascular mortality ( $n=314$; RR $0.44 ; 95 \% \mathrm{Cl} 0.29-0.68$ ), cardiovascular events ( $n=363$; RR $0.52 ; 95 \% \mathrm{Cl} 0.31-0.88$ ), or hospitalizations ( $n=314$; RR $0.61 ; 95 \% \mathrm{Cl} 0.48-0.78$ ) in dialysis patients. The observational studies showed significant difference in all-cause mortality $(n=35,233$; hazard ratio [HR] $0.86 ; 95 \% \mathrm{Cl} 0.80-0.92$ ) between $\beta$-blockers and no $\beta$-blockers
\end{abstract}

therapy in patients with dialysis, while the studies showed no difference in cardiovascular mortality ( $n=19,413$; HR 0.79; 95\% Cl 0.57-1.11), or cardiovascular events ( $n=$ 87,060; HR 0.79; 95\% Cl 0.50-1.26). Conclusions: $\beta$-blockers seem to be associated with reduced mortality in patients on dialysis. Both the statistical heterogeneity in observational studies and the small number of participants and studies in RCTs limit the strength of these findings. Video Journal Club "Cappuccino with Claudio Ronco" at https://www. karger.com/Journal/ArticleNews/496083?sponsor=52

(c) 2019 S. Karger AG, Basel

\section{Introduction}

It is well known that patients on dialysis are at increased risk of cardiovascular mortality and morbidity [1, 2]. Congestive heart failure (HF), coronary artery disease, arrhythmia, and cardiac arrest are common cardiovascular conditions and predispose to death, which accounts for approximately $50 \%$ of all deaths in this population [3-5]. Currently, it remains a huge challenge to improve survival rate due to complex pathophysiology and lack of evidence-based drug therapy strategies in dialysis patients [6].

\section{KARGER}

(c) 2019 S. Karger AG, Basel

E-Mail karger@karger.com

www.karger.com/bpu
Qiyao Yu, MD

Department of Scientific Research

The Fourth Hospital of Hebei Medical University

Jiankang Road, Shijiazhuang 050011 (PR China)

E-Mail yumnn9@163.com 
It has been shown that sympathetic nervous system is overactivated and harmful to cardiovascular events in patients with dialysis [7-9]. Reasonably, $\beta$-adrenergic antagonists, which have been well used in non-renal disease patients with cardiovascular disease for improving the outcomes [10-12], may play a protective role in dialysis population. Moreover, the study from US Renal Data System data exhibits that higher utilization rate of $\beta$-blockers is associated with higher survival rate in dialysis patients [13]. However, the utilization of $\beta$-blockers in dialysis patients varies ranging from as few as $10 \%$ of patients in Japan to approximately $60 \%$ in United States [14]. The reason may be that evidence on the benefits of $\beta$-blockers in patients receiving dialysis is insufficient currently. Most randomized controlled trials (RCTs) on $\beta$-blockers have excluded patients with advanced chronic kidney disease due to the risk of side effects, such as fluid overload, intradialytic muscle cramping, hypotension, and hyperkalemia [15-18], whereas some observational studies have demonstrated better survival and cardiovascular outcomes in dialysis patients treated with $\beta$-blockers [19, $20]$.

Therefore, we conducted a systematic review and meta-analysis on RCTs and observational studies to explore the effects of $\beta$-blockers in patients treated with dialysis.

\section{Materials and Methods}

\section{Search Strategy and Study Selection}

In this meta-analysis, we complied with the Preferred Reporting Items for Systematic Reviews and Meta-Analyses guideline [21] for RCTs and the Meta-Analysis of Observational Studies in Epidemiology guideline [22] for observational studies. The literature published from inception to May 2018 was searched using MEDLINE (PubMed), EMBASE databases, and the Cochrane Central Register. MeSH terms and free text "dialysis", "hemodialysis", "renal replacement therapy", "peritoneal dialysis", "adrenergic beta antagonists", "beta adrenergic blocking agents", "adrenergic beta blockers", "beta blockers" were used individually and in various combinations with AND or OR to obtain all RCTs and observational studies about the role of beta blockers in dialysis population. We also hand-searched references of review articles to identify additional studies. Articles were included without any restriction on sample size and language.

Two independent investigators (J.J. and X.G.) assessed the articles by titles and abstracts; then studies that met the inclusion criteria were retrieved for full-text assessment. Disagreements were resolved through discussion or referral to a third investigator (Q.Y.), and final decisions were made by consensus.

\section{Selection Criteria}

The following predefined inclusion criteria were used to select the eligible studies:

(1) Participants: adult dialysis population.

(2) Interventions: The group on $\beta$-blockers treatment.

(3) Comparisons: The group not on $\beta$-blockers treatment.

(4) Outcomes: All-cause and cardiovascular mortality, cardiovascular events, and hospitalizations.

(5) Study design: Both RCTs and observational studies.

We excluded studies on patients with acute and serious coexisting illnesses requiring intensive care, articles without available data, conference abstracts, and reviews.

\section{Data Extraction and Quality Assessment}

For each eligible study, general information (first author, year of publication, year of study, study name, sample size), baseline demographic and clinical characteristics of participants (duration of dialysis, comorbidities, concomitant renin-angiotensin-aldosterone system inhibition, follow-up), interventions/exposure ( $\beta$-blockers treatment and no $\beta$-blockers treatment), and outcome data (cardiovascular events, all-cause and cardiovascular mortality, and hospitalizations) were recorded.

For RCTs, 2 reviewers (J.J. and X.G.) evaluated risk of bias of studies according to the Cochrane Collaboration tool [23]. The following 6 items were assessed: (1) random sequence generation; (2) allocation concealment; (3) blinding; (4) incomplete outcome data; (5) selective outcome reporting; and (6) any other bias (e.g., insufficient rationale, study design). For observational studies, the Newcastle-Ottawa Scale [24] was used to assess their quality of reporting by the reviewers (J.J. and X.G.). Bias was assessed in the following domains: selection of study groups, comparability of groups, and ascertainment of the exposure or outcome of interest. Conflict was resolved by the third reviewer (Q.Y.).

\section{Ethical Approval}

No ethical approval was required because the data were extracted from previously published articles.

\section{Statistical Analysis}

We tabulated characteristics of all included studies. For RCTs, risk ratio (RR) with 95\% CI was presented for dichotomous outcomes, and hazard ratio (HR) with $95 \%$ CI for observational studies. For studies that did not provide HR, RR was used to estimate the HR. Fixed effects models by inverse variance methods were used when there was no heterogeneity, whereas random effects models by DerSimonian-Laird methods were applied when there was obvious heterogeneity. $p<0.05$ denoted a statistically significant difference.

The Cochran Q test was used to assess heterogeneity among studies. Heterogeneity was considered present if the $p$ value was less than 0.05 or $I^{2}$ was more than $50 \%$.

Then we did sensitivity analyses by removing each study stepwise to explore the effect of individual study on the overall estimates. We assessed the possibility of publication bias by constructing a funnel plot of each trial's effect size against the standard error. We assessed funnel plot asymmetry using Begg's and Egger's tests and defined significant publication bias as $p$ value $<0.05$. We used Stata (version 12.0 ) for all statistical analyses.
Jin/Guo/Yu 
Table 1. Characteristics of RCTs

\begin{tabular}{|c|c|c|c|c|c|c|c|c|c|c|}
\hline $\begin{array}{l}\text { Study: first } \\
\text { author, } \\
\text { year of } \\
\text { publication, } \\
\text { year of } \\
\text { study, study } \\
\text { name }\end{array}$ & Country & $\begin{array}{l}\text { Participants, } \\
n\end{array}$ & $\begin{array}{l}\text { Age, } \\
\text { years, } \\
\text { mean }\end{array}$ & $\begin{array}{l}\text { Duration } \\
\text { of dialysis }\end{array}$ & $\begin{array}{l}\text { Comorbidities } \\
\text { (disease, \%) }\end{array}$ & Exposure & Control & $\begin{array}{l}\text { Concomitant } \\
\text { RAAS } \\
\text { inhibition, \% }\end{array}$ & Follow-up & Outcomes \\
\hline $\begin{array}{l}\text { Cice [27], } \\
2003, \\
1996-1998, \\
\text { N/A }\end{array}$ & Italy & $\begin{array}{l}\text { dialysis } \\
\text { patients } \\
(n=114)\end{array}$ & 55.0 & $\begin{array}{l}83.7 \\
\text { months }\end{array}$ & $\begin{array}{l}\text { Heart failure, } \\
100\end{array}$ & Carvedilol & Placebo & 100 & 2 years & $\begin{array}{l}\text { All-cause } \\
\text { mortality } \\
\text { Cardiovascular } \\
\text { mortality } \\
\text { Cardiovascular } \\
\text { events } \\
\text { Hospitalizations }\end{array}$ \\
\hline $\begin{array}{l}\text { Agarwal } \\
{[25], 2014,} \\
2005-2013, \\
\text { HDPAL }\end{array}$ & U.S & $\begin{array}{l}\text { dialysis } \\
\text { patients } \\
(n=200)\end{array}$ & 52.7 & $\begin{array}{c}4.1 \\
\text { years }\end{array}$ & $\begin{array}{l}\text { Hypertension, } \\
100 \\
\text { Left-ventricular } \\
\text { hypertrophy, } \\
100 \\
\text { Diabetes, } 43 \\
\text { Coronary } \\
\text { disease, } 26.5\end{array}$ & Atenolol & Lisinopril & 71.5 & 12 months & $\begin{array}{l}\text { Cardiovascular } \\
\text { mortality } \\
\text { Cardiovascular } \\
\text { events } \\
\text { Hospitalizations }\end{array}$ \\
\hline $\begin{array}{l}\text { Roberts [9], } \\
2016, \\
2011-2012, \\
\text { BLOCADE }\end{array}$ & $\begin{array}{l}\text { Australia } \\
\text { and New } \\
\text { Zealand }\end{array}$ & $\begin{array}{l}\text { dialysis } \\
\text { patients } \\
(n=49)\end{array}$ & 58.6 & $\begin{array}{r}3-36 \\
\text { months }\end{array}$ & $\begin{array}{l}\text { Diabetes, } 63.2 \\
\text { Coronary } \\
\text { disease, } 12.2 \\
\text { Hypertension, } \\
89.8\end{array}$ & Carvedilol & Placebo & 36.7 & 12 months & $\begin{array}{l}\text { All-cause } \\
\text { mortality } \\
\text { Cardiovascular } \\
\text { events }\end{array}$ \\
\hline
\end{tabular}

RCT, randomized, controlled trial; RAAS, renin-angiotensin-aldosterone system; N/A, not applicable; ACEI, angiotensin-converting enzyme inhibitors; ARB, angiotensin II receptor antagonists; HDPAL, hypertension in hemodialysis patients treated with atenolol or lisinopril; BLOCADE, the $\beta$-Blocker to lower cardiovascular dialysis events.

\section{Results}

We identified 4,284 references in total, of which 4,236 were excluded based on screening of titles and abstracts, and 48 were evaluated further by full text, including 3 RCTs [9, 25-28] and 9 observational studies finally deemed eligible for inclusion [19, 20, 29-35].

\section{Randomized Controlled Trials}

Characteristics of selected studies. Table 1 shows the characteristics and main outcomes extracted from the RCTs studies. Among these 3 RCTs, one study population was dialysis patients with HF [26], and another one with hypertension and left-ventricular hypertrophy [25]. Two studies compared carvedilol with placebo, and the last one by Agarwal et al. [25] compared atenolol with lisinopril. All studies reported all-cause mortality and cardiovascular events, but the outcomes of cardiovascular mortality and hospitalizations were collected only in 2 studies by Cice et al. $[26,27]$ and Agarwal et al. [25].

Effects of Beta-Blockers on Cardiovascular Events and Mortality in Dialysis Patients
Quality of reporting and risk of bias. The risk of bias assessment of the individual study. Random sequence generation was not adequately described in the study by Cice et al. [26, 27]. The studies by Cice et al. [26, 27] and Agarwal et al. [25] were labeled as no blinding due to open-label trials so that other bias was possible.

All-cause mortality. In the pooled analysis of 3 studies $(n=363)$, compared with no $\beta$-blockers treatment, $\beta$-blockers reduced all-cause mortality in dialysis patients: RR $0.73 ; 95 \%$ CI $0.54-0.97 ; p=0.028$ in the random effects model (Fig. 1a). There was no heterogeneity among studies ( $\left.p=0.637, I^{2}=0 \%\right)$. Egger's test did not find significant evidence of publication bias $(p=0.118)$. However, sensitivity analysis indicated that the beneficial effect of $\beta$-blockers on all-cause mortality had disappeared with the exclusion of the study by Cice et al. $[26,27]$ (RR 1.17; 95\% CI 0.33-4.06).

Cardiovascular mortality. In the pooled analysis of 2 studies $(n=314), \beta$-blockers reduced cardiovascular mortality in dialysis patients with basic heart disease compared with no $\beta$-blockers treatment: RR 0.44; 95\% CI 
$0.29-0.68 ; p<0.001$ in the random effects model (Fig. 1b). There was no heterogeneity between the 2 studies ( $p=$ $\left.0.640, I^{2}=0 \%\right)$.

Cardiovascular events. Meta-analysis of 3 studies $(n=$ 363) showed significant decline in cardiovascular events with $\beta$-blockers treatment: RR 0.52; 95\% CI 0.31-0.88; $p=0.014$ in the random effects model (Fig. 1c). There was no heterogeneity among studies $\left(p=0.652, I^{2}=0 \%\right)$. Egger's test found significant evidence of publication bias $(p=0.016)$. And sensitivity analysis indicated that there was no difference in the effects of $\beta$-blockers and placebo on cardiovascular events with the exclusion of the study by Agarwal et al. [25].

Hospitalizations. Meta-analysis of 2 studies $(n=314)$ showed noticeable reduction in hospitalizations with $\beta$-blockers treatment: RR 0.61; 95\% CI 0.48-0.78; $p<$ 0.001 in the random effects model (Fig. 1d). There was no heterogeneity between them $\left(p=0.792, I^{2}=0 \%\right)$.

\section{Observational Studies}

Characteristics of selected studies. Studies and participants characteristics were summarized in Table 2. Nine studies compared "any $\beta$-blocker regimen" with "no $\beta$-blockers treatment". Five studies reported all-cause mortality, 3 studies reported cardiovascular mortality, and 3 studies reported cardiovascular events. Only one study reported hospitalizations, so meta-analysis was not possible for it.

Quality of reporting and risk of bias. Nine studies were found to have a low risk of bias in all categories.

All-cause mortality. Meta-analysis of 5 studies $(n=$ $35,233)$ showed significant difference in all-cause mortality between $\beta$-blockers and no $\beta$-blockers therapy: HR 0.86 ; $95 \%$ CI $0.80-0.92 ; p<0.001$ in the random effects model (Fig. 2a). There was no evident heterogeneity among studies $\left(p=0.097 ; I^{2}=49.1 \%\right)$. Egger's test did not find significant evidence of publication bias $(p=$ 0.337 ). Further sensitivity analysis indicated that the beneficial effect of $\beta$-blockers on all-cause mortality did not substantially differ with the exclusion of any individual study.

Cardiovascular mortality. Meta-analysis of 3 studies $(n=19,413)$ showed no association between cardiovascular mortality and $\beta$-blockers treatment: HR 0.79; 95\% CI $0.57-1.11 ; p=0.17$ in the random effects model (Fig. 2b). There was considerable heterogeneity among studies $(p=$ $\left.0.069 ; I^{2}=62.5 \%\right)$. Egger's test did not find significant evidence of publication bias $(p=0.424)$. Sensitivity analysis indicated that the study by Matsue et al. [29] had great heterogeneity with other studies.
Cardiovascular events. Meta-analysis of 3 studies $(n=$ $87,060)$ showed no association between cardiovascular events and $\beta$-blockers treatment: HR 0.79; 95\% CI 0.501.26; $p=0.324$ in the random effects model (Fig. 2 c). There was considerable heterogeneity among studies $(p<$ $\left.0.001 ; I^{2}=93.6 \%\right)$. Egger's test did not find significant evidence of publication bias $(p=0.05)$. Sensitivity analysis indicated that results remained unchanged with the exclusion of any individual study

\section{Discussion}

In this systematic review and meta-analysis of 3 RCTs and 9 observational studies of $>120,000$ dialysis participants, we observed a $27 \%$ relative reduction in all-cause mortality, a $56 \%$ relative reduction in cardiovascular mortality with $\beta$-blockers therapy in RCTs, and a $14 \%$ relative reduction in all-cause mortality in observational studies.

Given the high incidence of cardiovascular disease, dialysis patients may benefit from $\beta$-blockers therapy, which is the same as that observed in other populations [36-38]. Previously, Badve et al. [14] performed a meta-analysis on RCTs addressing the efficacy and safety of $\beta$-blockers in CKD patients and found that treatment with $\beta$-blockers improved survival in patients with chronic HF. Their findings mainly targeting the non-dialysis population confirmed our results in dialysis patients. Additionally, $\beta$-blockers were superior in improving arterial stiffness, left ventricular function, and long-term control of hypertension in dialysis patients so that they were able to reduce malignant cardiovascular events [39-41]. In this systematic review, data regarding incorporated RCTs displayed that the benefits of $\beta$-blockers for all-cause mortality, cardiovascular mortality, cardiovascular events, and hospitalizations in dialysis patients were similar to those in people who did not receive dialysis. However, sensitivity analysis indicated that the results on all-cause mortality and cardiovascular events were not stable. One of the reasons may be associated with comorbidities of different study subjects. In the study by Cice et al. [26, 27], dialysis patients, coexisting HF, may benefit much more from the treatment of $\beta$-blockers, thus it takes more weight in the result of all-cause mortality. Another reason may be related to the sample size. The study by Agarwal et al. [25] included most of the patients, so it may be primarily responsible for the result of cardiovascular events. For included observational trials, we also found $\beta$-blockers were associated with a reduction in all-cause mortality. Of note, a possibility of benefits for cardiovascular mortality 


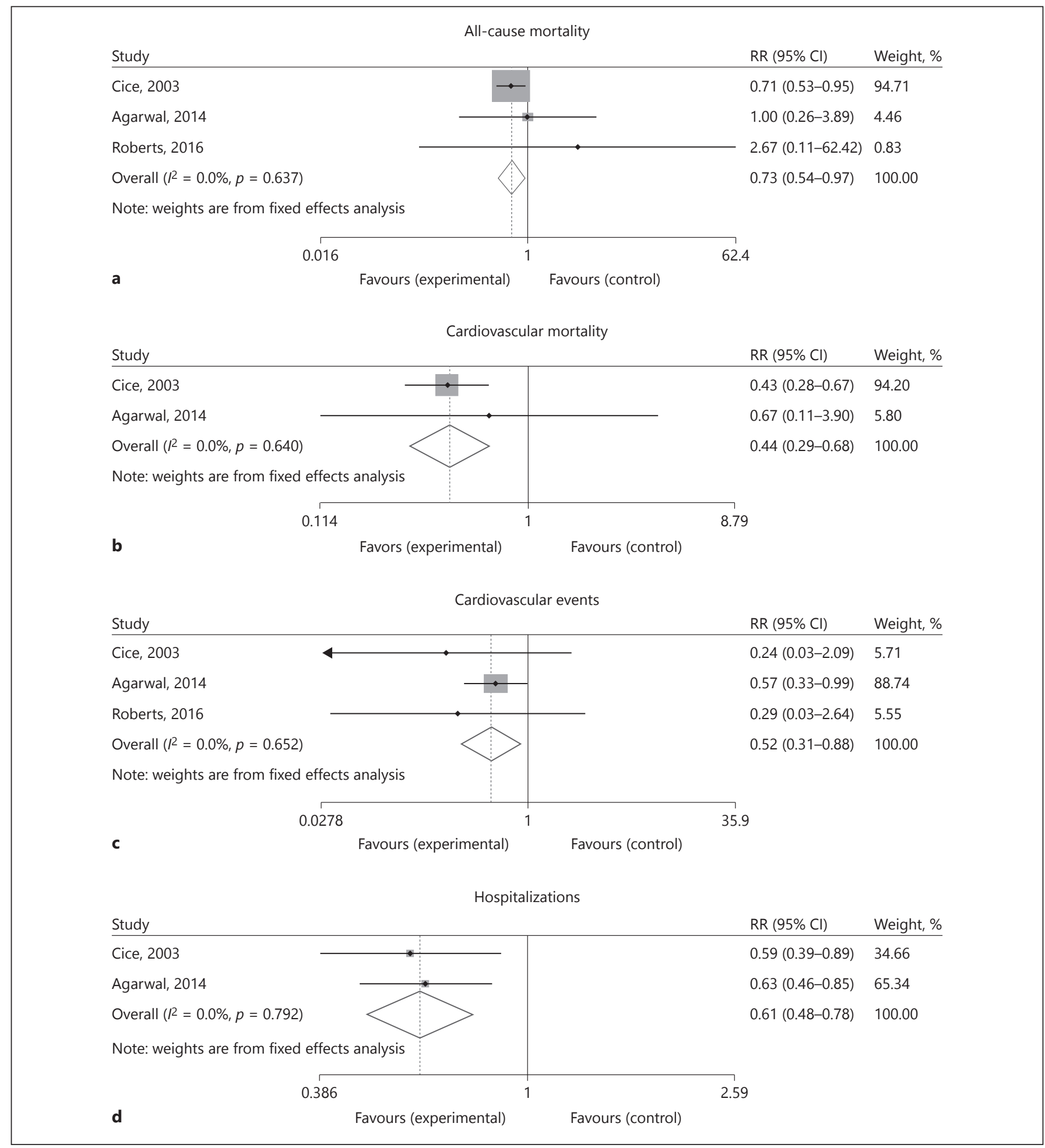

Fig. 1. Statistically significant difference in all-cause mortality, cardiovascular mortality, cardiovascular events, or hospitalizations in meta-analyses of RCTs. Meta-analysis comparing the effects of $\beta$-blockers versus control in RCTs. a All-cause mortality. b Cardiovascular mortality. c Cardiovascular events. d Hospitalizations. $\mathrm{RR}$, risk ratio.
Effects of Beta-Blockers on Cardiovascular Events and Mortality in Dialysis Patients 


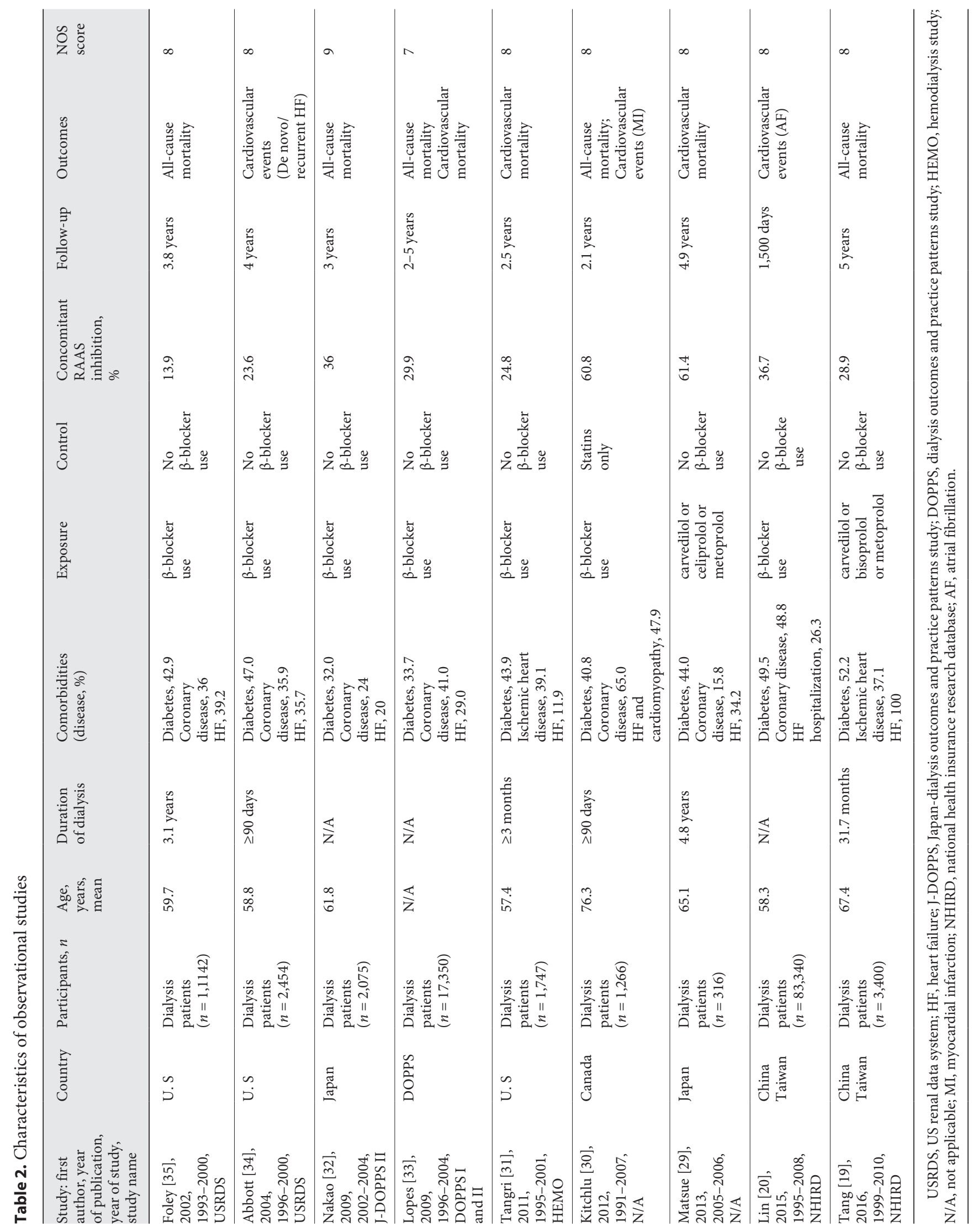




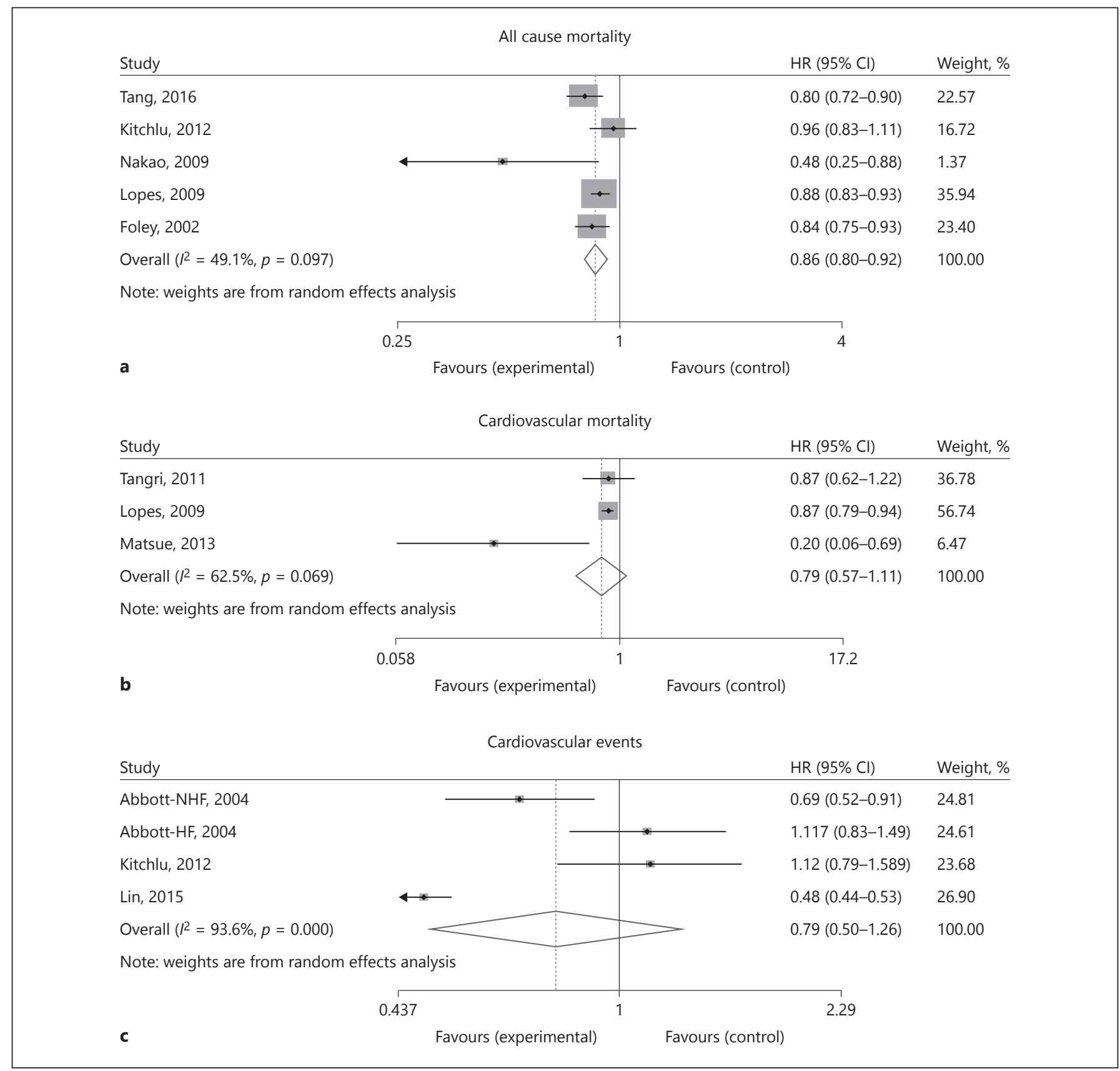

Fig. 2. Statistically significant difference in all-cause mortality but no significant difference in either cardiovascular mortality, or cardiovascular events in meta-analyses of observational studies. Meta-analysis comparing the effects of $\beta$-blockers versus control in observational studies. a All-cause mortality. b Cardiovascular mortality. c Cardiovascular events. HR, hazard ratio; HF, heart failure; NHF, no HF. and events was also observed with a no statistically significant trend. Further analysis showed that study by Matsue et al. [29] was heterogeneous with the other 2 studies. One of the reasons may be associated with duration of $\beta$-blockers. In the study by Matsue et al. [29], all patients were followed-up until death with treatment of $\beta$-blockers, while patients in the other 2 studies were not. Hence, Matsue's research was more convincing, and it showed $\beta$-blockers use in the dialysis population may substantially improve outcome. In short, considering that dialysis 
patients have a higher epidemiology of cardiovascular disease, the absolute risk reduction with $\beta$-blockers therapy may be much greater in this population. Of course, additional randomized trials are needed to strengthen these findings.

Our findings suggest that use of $\beta$-blockers may be beneficial in dialysis patients, however, in this metaanalysis we cannot reveal which specific $\beta$-blocker is safe and effective. Compared with other drugs, selecting an appropriate $\beta$-blocker is difficult because of pharmacodynamics, pharmacokinetics, and side effects. Especially, for dialysis patients, $\beta$-blockers dialyzability has a significant impact on the efficacy. In a large retrospective cohort study, dialysis patients with a poorly dialyzed $\beta$-blocker (bisoprolol) had a larger survival rate than those with a highly dialyzable $\beta$-blocker (atenolol or metoprolol) [42]. However, based on the RCTs we have included, dialysis patients with HF would get carvedilol and those with left-ventricular hypertrophy would get atenolol. Recently, Roberts et al. [9] reported intradialytic hypotension with carvedilol, whereas Agarwal et al. [25] found no such signal. So, it is controversial for the choice of $\beta$-blockers.

The strength of this study is including both RCTs and observational studies. Although the number of studies and participants was limited in the RCTs, the observational studies included much larger sample sizes. We are confident in our description of the current literature but advise caution in applying our results. There are some limitations in our study. First, despite detailed adjustment for potential confounders, observational studies can never eliminate the influence of reporting and indication bias. Second, as there is a strong relation between mortality and dialyzability of the drugs, the findings for beta blockers are generalizable. Thus, exploring specific $\beta$-blockers and reasonable dosages in dialysis patients is imminent.

\section{Conclusions}

In this systematic review and meta-analysis, we find the evidence of reduced all-cause mortality, cardiovascular mortality, cardiovascular events, and hospitalizations in RCTs as well as relative reduction of all-cause mortality in observational studies in dialysis patients with $\beta$-blockers therapy. The statistical heterogeneity noted in observational studies and the small number of participants and studies in RCTs limit our findings about beneficial effects of $\beta$-blockers. Hence, reasonable and large RCTs are needed to strengthen these results.

\section{Acknowledgments}

This research did not receive any specific grant from funding agencies in the public, commercial, or not-for-profit sectors.

\section{Disclosure Statement}

All the authors declare that there are no competing financial interests in relation to the work described.

\section{References}

1 Whalley GA, Marwick TH, Doughty RN, Cooper BA, Johnson DW, Pilmore A, et al.; IDEAL Echo Substudy Investigators. Effect of early initiation of dialysis on cardiac structure and function: results from the echo substudy of the IDEAL trial. Am J Kidney Dis. 2013 Feb;61(2):262-70.

2 Roberts MA, Polkinghorne KR, McDonald SP, Ierino FL. Secular trends in cardiovascular mortality rates of patients receiving dialysis compared with the general population. Am J Kidney Dis. 2011 Jul;58(1):64-72.

3 Heerspink HJ, Ninomiya T, Zoungas S, de Zeeuw D, Grobbee DE, Jardine MJ, et al. Effect of lowering blood pressure on cardiovascular events and mortality in patients on dialysis: a systematic review and meta-analysis of randomised controlled trials. Lancet. 2009 Mar;373(9668): 1009-15.
4 Saran R, Robinson B, Abbott KC, Agodoa LYC, Bhave N, Bragg-Gresham J, Balkrishnan R, et al. US Renal Data System 2017 Annual Data Report: Epidemiology of Kidney Disease in the United States. Am J Kidney Dis. 2018 Mar;71(3S1):A7.

5 Furgeson SB, Chonchol M. Beta-blockade in chronic dialysis patients. Semin Dial. 2008 Jan-Feb;21(1):43-8.

6 Weir MA, Herzog CA. Beta blockers in patients with end-stage renal disease-Evidencebased recommendations. Semin Dial. 2018 May;31(3):219-25.

7 Daugirdas JT. Pathophysiology of dialysis hypotension: an update. Am J Kidney Dis. 2001 Oct;38(4 Suppl 4):S11-7.

8 Converse RL Jr, Jacobsen TN, Toto RD, Jost $\mathrm{CM}$, Cosentino F, Fouad-Tarazi F, et al. Sympathetic overactivity in patients with chronic renal failure. NEnglJMed.1992 Dec;327(27):1912-8.
9 Roberts MA, Pilmore HL, Ierino FL, Badve SV, Cass A, Garg AX, et al.; BLOCADE Study Collaborative Group. The $\beta$-Blocker to Lower Cardiovascular Dialysis Events (BLOCADE) Feasibility Study: A Randomized Controlled Trial. Am J Kidney Dis. 2016 Jun;67(6):902-11.

10 Lindholm LH, Ibsen H, Dahlöf B, Devereux RB, Beevers G, de Faire U, et al.; LIFE Study Group. Cardiovascular morbidity and mortality in patients with diabetes in the Losartan Intervention For Endpoint reduction in hypertension study (LIFE): a randomised trial against atenolol. Lancet. 2002 Mar;359(9311):1004-10.

11 Yang JH, Hahn JY, Song YB, Choi SH, Choi $\mathrm{JH}$, Lee SH, et al. Association of beta-blocker therapy at discharge with clinical outcomes in patients with ST-segment elevation myocardial infarction undergoing primary percutaneous coronary intervention. JACC Cardiovasc Interv. 2014 Jun;7(6):592-601. 
12 Shibata MC, Flather MD, Wang D. Systematic review of the impact of beta blockers on mortality and hospital admissions in heart failure. Eur J Heart Fail. 2001 Jun;3(3): $351-7$.

13 Tang Y, Brooks JM, Wetmore JB, Shireman TI. Association between higher rates of cardioprotective drug use and survival in patients on dialysis. Res Social Adm Pharm. 2015 Nov-Dec;11(6):824-43.

14 Badve SV, Roberts MA, Hawley CM, Cass A, Garg AX, Krum H, et al. Effects of beta-adrenergic antagonists in patients with chronic kidney disease: a systematic review and metaanalysis. J Am Coll Cardiol. 2011 Sep;58(11): 1152-61.

15 Nowicki M, Szewczyk-Seifert G, Klimek D, Kokot F. Carvedilol does not modulate moderate exercise-induced hyperkalemia in hemodialysis patients. Clin Nephrol. 2002 May; 57(5):352-8.

16 Hahn L, Hahn M. Carvedilol-induced hyperkalemia in a patient with chronic kidney disease. J Pharm Pract. 2015 Feb;28(1):107-11.

17 Nowicki M, Miszczak-Kuban J. Nonselective Beta-adrenergic blockade augments fasting hyperkalemia in hemodialysis patients. Nephron. 2002 Jun;91(2):222-7.

18 Bi SH, Linke L, Wu J, Cheng LT, Wang T, Ahmad S. Effects of beta-blocker use on volume status in hemodialysis patients. Blood Purif. 2012;33(4):311-6.

19 Tang CH, Wang CC, Chen TH, Hong CY, Sue YM. Prognostic Benefits of Carvedilol, Bisoprolol, and Metoprolol Controlled Release/ Extended Release in Hemodialysis Patients with Heart Failure: A 10-Year Cohort. J Am Heart Assoc. 2016 Jan;5(1):e002584.

20 Lin TT, Chiang JY, Liao MT, Tsai CT, Hwang JJ, Chiang FT, et al. Primary prevention of atrial fibrillation with beta-blockers in patients with end-stage renal disease undergoing dialysis. Sci Rep. 2015 Dec;5(1):17731.

21 Moher D, Liberati A, Tetzlaff J, Altman DG; PRISMA Group. Preferred reporting items for systematic reviews and meta-analyses: the PRISMA statement. J Clin Epidemiol. 2009 Oct;62(10):1006-12.

22 Stroup DF, Berlin JA, Morton SC, Olkin I, Williamson GD, Rennie D, et al. Meta-analysis of observational studies in epidemiology: a proposal for reporting. Meta-analysis Of Observational Studies in Epidemiology (MOOSE) group. JAMA. 2000 Apr;283(15): 2008-12.
23 Higgins JP, Altman DG, Gøtzsche PC, Jüni P, Moher D, Oxman AD, et al.; Cochrane Bias Methods Group; Cochrane Statistical Methods Group. The Cochrane Collaboration's tool for assessing risk of bias in randomised trials. BMJ. 2011 Oct;343 oct18 2:d5928.

24 Kakati B, Krishna S, Sharma S, Rego R. Pseudomelanosis duodeni: a rare finding from upper endoscopy. Dig Endosc. 2011 Apr;23(2): 201-2.

25 Agarwal R, Sinha AD, Pappas MK, Abraham TN, Tegegne GG. Hypertension in hemodialysis patients treated with atenolol or lisinopril: a randomized controlled trial. Nephrol Dial Transplant. 2014 Mar;29(3):672-81.

26 Cice G, Ferrara L, Di Benedetto A, Russo PE, Marinelli G, Pavese F, et al. Dilated cardiomyopathy in dialysis patients-beneficial effects of carvedilol: a double-blind, placebo-controlled trial. J Am Coll Cardiol. 2001 Feb; 37(2):407-11.

27 Cice G, Ferrara L, D'Andrea A, D'Isa S, Di Benedetto A, Cittadini A, et al. Carvedilol increases two-year survivalin dialysis patients with dilated cardiomyopathy: a prospective, placebo-controlled trial. J Am Coll Cardiol. 2003 May;41(9):1438-44.

28 Roberts MA, Darssan D, Badve SV, Carroll RP, Fahim MA, Haluska BA, et al. Carvedilol and Cardiac Biomarkers in Dialysis Patients: Secondary Analysis of a Randomized Controlled Trial. Kidney Blood Press Res. 2017; 42(6):1033-44.

29 Matsue Y, Suzuki M, Nagahori W, Ohno M, Matsumura A, Hashimoto Y. $\beta$-blocker prevents sudden cardiac death in patients with hemodialysis. Int J Cardiol. 2013 May;165(3): 519-22.

30 Kitchlu A, Clemens K, Gomes T, Hackam DG, Juurlink DN, Mamdani M, et al. Betablockers and cardiovascular outcomes in dialysis patients: a cohort study in Ontario, Canada. Nephrol Dial Transplant. 2012 Apr; 27(4):1591-8.

31 Tangri N, Shastri S, Tighiouart H, Beck GJ, Cheung AK, Eknoyan G, et al. $\beta$-Blockers for prevention of sudden cardiac death in patients on hemodialysis: a propensity score analysis of the HEMO Study. Am J Kidney Dis. 2011 Dec;58(6):939-45.

32 Nakao K, Makino H, Morita S, Takahashi Y, Akizawa T, Saito A, et al.; J-DOPPS Investigators Group. Beta-blocker prescription and outcomes in hemodialysis patients from the Japan Dialysis Outcomes and Practice Patterns Study. Nephron Clin Pract. 2009; 113(3):c132-9.
33 Lopes AA, Bragg-Gresham JL, Ramirez SP, Andreucci VE, Akiba T, Saito A, et al. Prescription of antihypertensive agents to haemodialysis patients: time trends and associations with patient characteristics, country and survival in the DOPPS. Nephrol Dial Transplant. 2009 Sep;24(9): 2809-16.

34 Abbott KC, Trespalacios FC, Agodoa LY, Taylor AJ, Bakris GL. beta-Blocker use in long-term dialysis patients: association with hospitalized heart failure and mortality. Arch Intern Med. 2004 Dec;164(22): 2465-71.

35 Foley RN, Herzog CA, Collins AJ; United States Renal Data System. Blood pressure and long-term mortality in United States hemodialysis patients: USRDS Waves 3 and 4 Study. Kidney Int. 2002 Nov;62(5):178490.

36 Liu F, Chen Y, Feng X, Teng Z, Yuan Y, Bin J. Effects of beta-blockers on heart failure with preserved ejection fraction: a meta-analysis. PLoS One. 2014 Mar;9(3):e90555.

37 Bangalore S, Makani H, Radford M, Thakur K, Toklu B, Katz SD, et al. Clinical outcomes with $\beta$-blockers for myocardial infarction: a meta-analysis of randomized trials. Am J Med. 2014 Oct;127(10):939-53.

38 Cadrin-Tourigny J, Shohoudi A, Roy D, Talajic M, Tadros R, Mondésert B, et al. Decreased Mortality With Beta-Blockers in Patients With Heart Failure and Coexisting Atrial Fibrillation: an AF-CHF Substudy. JACC Heart Fail. 2017 Feb;5(2):99-106.

39 Hara Y, Hamada M, Shigematsu Y, Murakami B, Hiwada K. Beneficial effect of beta-adrenergic blockade on left ventricular function in haemodialysis patients. Clin Sci (Lond). 2001 Sep;101(3):219-25.

40 Georgianos PI, Agarwal R. Effect of lisinopril and atenolol on aortic stiffness in patients on hemodialysis. Clin J Am Soc Nephrol. 2015 Apr;10(4):639-45.

41 Vlassopoulos DA, Mentzikof DG, Hadjiyannakos DK, Noussias CV, Karras SM, Hadjiconstantinou VE. Long-term control of hypertension in dialysis patients by low dose atenolol. Int J Artif Organs. 2002 Apr;25(4): 269-75.

42 Weir MA, Dixon SN, Fleet JL, Roberts MA, Hackam DG, Oliver MJ, et al. $\beta$-Blocker dialyzability and mortality in older patients receiving hemodialysis. J Am Soc Nephrol. 2015 Apr;26(4):987-96.
Effects of Beta-Blockers on Cardiovascular Events and Mortality in Dialysis Patients 